\title{
Experience with a modified Macintosh laryngoscope as a video laryngoscope adapted to a USB camera and cellphone
}

\author{
Dionicio Palacios-Ríos, Roberto E. Nava-Vázquez*, Nora H. Rodríguez-Rodríguez, \\ Norma G. López-Cabrera and Gustavo González-Cordero
}

Department of Anesthesiology, School of Medicine, "José Eleuterio González" University Hospital, Autonomous University of Nuevo Leon, Monterrey, Nuevo Leon, Mexico

\begin{abstract}
Introduction: Management of the airway is one of the challenges in anesthesiology; multiple devices and techniques have been developed to manage it, preventing a catastrophic outcome for the patient in different scenarios. Objective: The objective of the study was to demonstrate that our modified laryngoscope, using a cell phone as a screen monitor, is useful and safe in the management of the adult patient's airway. Materials and methods: This was a descriptive, observational, and prospective study, using the modified laryngoscope for intubation in 139 elective patients, with airway check-up, intubation time measurement, number of attempts, observed Cormack-Lehane, percentage of glottis observed (POGO) scale, and adverse events registry. Results: There were 138 patients with successful intubations and one failure. Of these, $66.1 \%$ were female, and $33.9 \%$ were male, $92 \%$ were intubated on the first attempt. About $61 \%$ were intubated in $30 \mathrm{~s}$ or less and $35 \%$ in $<1$ min, visualization of the glottal ring was $82 \%, 72 \%$ of which were recorded as Cormack-Lehane I, and with POGOs of $100 \%$, the burp maneuver was used to assist in $38 \%$. Conclusions: The device proved to be useful and safe in the management of the patient's airway, with a success rate of $92 \%$ in the first attempt.
\end{abstract}

Key words: Video laryngoscope. Percentage of glottis observed score. Cell phone. USB camera. Intubation.

\section{Introduction}

Management of the airways, that is, the maneuvers and devices which allow proper and safe ventilation for patients who need it is one of the most important challenges with which a physician can be faced during clinical practice ${ }^{1}$.

"Difficult airway" is a clinical situation in which an anesthesiologist experiences difficulty in the ventilation facemask, endotracheal intubation, or both.

One of the most common factors which impede tracheal intubation is the lack of visualization of the vocal cords during direct laryngoscopy ${ }^{2}$. For this reason, new technologies are being developed to avoid this problem when a conventional direct laryngoscopy is used. Some of these include illuminated styli, rigid and flexible fiberscopes, and video laryngoscopes.

Among these devices, video-assisted techniques have become remarkably common in the management of the airways due to its effectiveness and safety. The flexible fiberscope is considered the gold standard in tracheal intubation. However, it has a significant learning curve, and a high level of dexterity is required in extremely difficult patients, which is not easy to accomplish due to the costs of the equipment necessary for

\section{Correspondence:}

*Roberto E. Nava-Vázquez

E-mail: rob_env@hotmail.com
Available online: 09-08-2019

Date of reception: 21-02-2019

DOI: 10.24875/RMU. 19000067
Medicina Universitaria. 2019;21(2):57-62 www.medicinauniversitaria.org

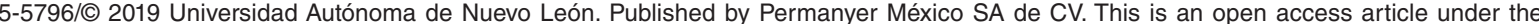
CC BY-NC-ND license (http://creativecommons.org/licenses/by-nc-nd/4.0/). 
its correct use. Video laryngoscopy is relatively new; it allows the direct visualization of the glottic aperture for the introduction of the endotracheal tube without substituting fiber optics. It is of great use for anesthesiologists in airway management since it has a shorter learning curve due to its similarity to the conventional laryngoscope and a considerably lower cost compared to other video-assisted methods. It presents some disadvantages, such as the need for an assistant, and it requires guides or stylet for its correct use.

Even the Difficult Airway Society and the American Society of Anesthesiologists (ASA) have added the use of a video laryngoscope as an assistant in the case of a difficult airway, either expected or not, to their protocols ${ }^{3,4}$.

The more video laryngoscopes are introduced in clinical practice; the more skill anesthesiologists acquire at this technique, which can simply resolve the approach of airways in the patient ${ }^{5}$.

Its benefit in patients with multiple traumas has been observed in the emergency room. Offering an advantage over direct laryngoscopy, which is the visualization of the airway by multiple people, and helping in the application of external maneuvers by a second assistant, this is helpful in endotracheal intubation training and teaching ${ }^{6}$.

In 2013, Dr. John George Karippacheril modified a conventional laryngoscope with a curved Mac 3 blade, adding a camera over it with tape, and thus obtaining a low-cost video laryngoscopy. This device was tested in 24 patients who were 15 years old or older, obtaining positive results in the approach of the airways of said patients ${ }^{7}$.

\section{Materials and methods \\ Objective}

The objective of the study was to demonstrate the fact that the video laryngoscope modified by our service is useful and safe in the management of airways in adult patients. Registering the number of attempts for successful intubation, the observed Cormack-Lehane, the percentage of glottis observed (POGO), intubation time and whether or not help with external maneuvers is needed, as well as socio-demographic variables.

For the completion of this study, a Macintosh \#3 laryngoscope blade was modified, adding a cylindrical metallic accessory (Figs. 1 and 2). We also used a $7 \mathrm{~mm}$ waterproof SUPEREYES ${ }^{\circledR}$ USB camera with a

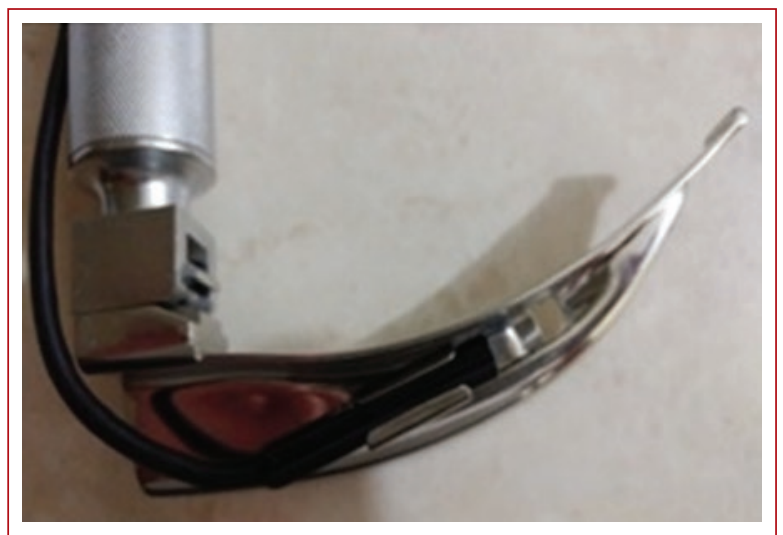

Figure 1. Camera mounted on a Mac \#3 blade, lateral view. Side view of the USB camera mounted on the cylindrical stainless steel attachment.

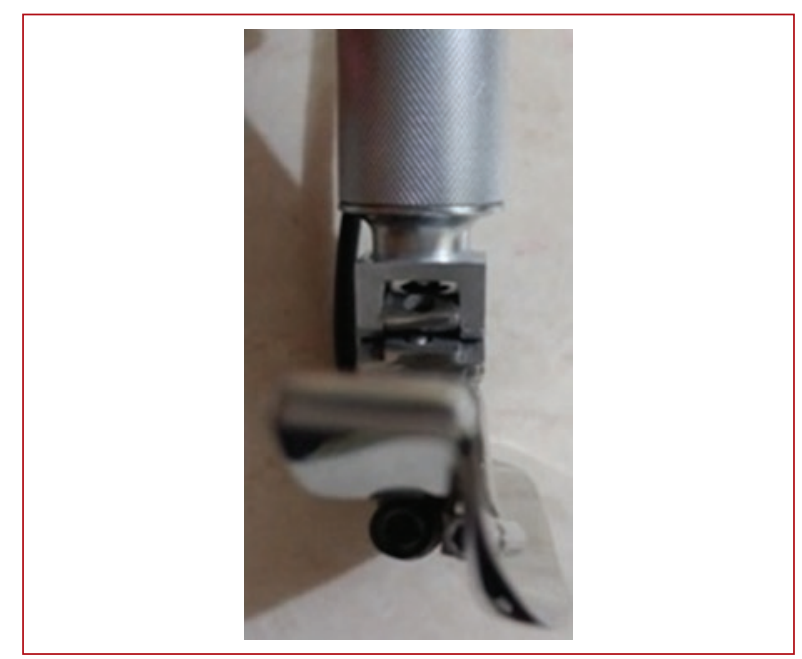

Figure 2. Camera mounted on a Mac \#3 blade, front view. Front view of the USB camera mounted on the cylindrical stainless steel attachment.

resolution of $640 \times 480$ pixels, and light-emitting diode illumination.

The camera was connected to a cellular phone with Android operating system (OS), with a $1.2 \mathrm{GHz}$ processor, a 5.1" screen, and a 3100 mAh battery. The utilized cable was a generic USB to micro USB cable. The camera used energy from the phone for illumination.

The gathering of the images was conducted through an application for mobile devices $\left(\right.$ CameraFi $\left.{ }^{\circledR}\right)$, which was obtained from the Android app store for free.

We used the ASA classification to evaluate the physical state of the patients as follows: I. A normal, healthy patient; II. A patient with a mild systemic disease, controlled and not incapacitating; and III. A patient with a 
systemic disease that is not incapacitating. Patients with ASA IV, V, and VI were not candidates for the study due to the severity of their conditions, so we disregarded these definitions.

Furthermore, intubation difficulty scales were used to assess the characteristics of the airways among our population.

\section{Mallampati score}

This evaluates the visualization of anatomical pharyngeal structures in the airway with the patient sitting down with a wide open mouth; Class I: soft palate, uvula, amygdaline pillars visible; Class II: soft palate, major part of the uvula visible; Class III: soft palate, base of uvula visible; and Class IV: impossible to view soft palate.

\section{Patil-Aldreti scale}

This measures the distance between the thyroid cartilage (superior notch) and the lower edge of the chin; it is performed with the patient sitting in the upright position, with head extended, and closed mouth; Class I: more than $6.5 \mathrm{~cm}$; Class II: from 6 to $6.5 \mathrm{~cm}$; and Class III: less than $6 \mathrm{~cm}$.

\section{Bellhouse-Dore scale}

This evaluates the extension of atlanto-occipital joint with regard to the normal $35^{\circ}$ : Grade I: no limitation; Grade II: 1/3; Grade III 2/3; and Grade IV: complete limitation.

\section{The Cormack-Lehane scale}

This is used in laryngoscopy and assesses four grades of difficulty for endotracheal intubation when performing a laryngoscopy, depending on the anatomical structures visualized: Grade I: glottic opening is visible in its entirety; Grade II: only the commissure or upper half of the glottic opening is visible; Grade III: only the epiglottis is visible with no visualization of the glottic opening; and Grade IV: impossible to visualize even the epiglottis. Just as in POGO, we divided patients into four groups to facilitate the gathering of data, at $<25 \%, 50 \%$, $75 \%$, and $100 \%$ visualization of the glottis.

Previously authorized by the etics committee of our institution (AN17-00009) and under informed consent of each patient, our study, which is proscriptive, descriptive and observational, was carried out in elective patients, in the central operating room of the University Hospital "Dr. Jose Eleuterio Gonzalez "who required endotracheal intubation for general anesthesia, were older than 18 years, with an ASA I-III, and an index of body mass less than 35 .

With pre-anesthetic evaluation and signed informed consents, the patients were taken into the odd ratio, where vital signs were monitored. Simultaneously, the video laryngoscopy equipment was prepared with the corresponding activation of the mobile application and verification of its correct use.

Anesthetic induction was initiated, with propofol at $2 \mathrm{mg} / \mathrm{kg}$, fentanyl at $3 \mu \mathrm{g} / \mathrm{kg}$, and rocuronium at $0.6 \mathrm{mg} / \mathrm{kg}$. Intubation with our device was performed, registering the time in seconds, number of attempts, Cormack-Lehane and POGO's immediately, conducting a revision of the correct position and fixation of the endotracheal tube, and registering any complications.

The statistical analysis was performed using SPSS with descriptive measures and means, and standard and inferential deviations, i.e., the Student's t-test and Chi-square for univariate analysis.

\section{Results}

A total of 139 patients were studied. The average age was $42.85 \pm 17.88$ years, who were programmed for elective surgery at the "Dr. Jose E. Gonzalez" University Hospital. Of these, 92 were female (66.1\%) and 47 were male (33.9\%).

An assessment of the airway was conducted in every patient, including the following scales: ASA, Mallampati, Patil-Aldreti, Bellhouse-Dore, and oral opening (Table 1).

The vast majority of recruited patients did not present predictive data of a difficult airway, except for four patients with Mallampati IV and five patients with an oral opening of $3 \mathrm{~cm}$; however, these patients did not present predictive data of a difficult airway, hence they remained as candidates to participate in the study without putting their health at risk.

Moreover, large percentages were healthy patients or patients with controlled chronic disease (ASA I and II), except for eight patients who presented ASA III (Table 1).

Intubation was successful in 138 patients out of 139 (99.2\%), intubation could not be accomplished in only one patient due to equipment failure. One hundred and twenty-eight patients were intubated on the first try $(92.8 \%)$, the time for intubation was under $30 \mathrm{~s}$ in 85 patients $(61.6 \%)$, the Cormack-Lehane was 
Table 1. Evaluation of the airways of the study subjects

\begin{tabular}{|c|c|}
\hline Criterion & Value (\%) \\
\hline $\begin{array}{l}\text { ASA } \\
\text { I } \\
\text { II } \\
\text { III }\end{array}$ & $\begin{array}{c}69(50) \\
61(44.2) \\
8(5.8)\end{array}$ \\
\hline $\begin{array}{l}\text { Mallampati } \\
\text { I } \\
\text { II } \\
\text { III } \\
\text { IV }\end{array}$ & $\begin{array}{c}76(55.1) \\
43(31.2) \\
17(12.3) \\
2(1.4)\end{array}$ \\
\hline $\begin{array}{l}\text { Patil-Aldreti } \\
\text { I } \\
\text { II }\end{array}$ & $\begin{array}{c}111(80.4) \\
27(19.6)\end{array}$ \\
\hline $\begin{array}{l}\text { Bellhouse-Dore } \\
\text { I }\end{array}$ & $138(100)$ \\
\hline $\begin{array}{l}\text { Oral aperture } \\
\text { More than } 3 \mathrm{~cm} \\
<3 \mathrm{~cm} \\
\text { History of difficult intubation }\end{array}$ & $\begin{array}{c}133(96.4) \\
5(3.6) \\
0(0)\end{array}$ \\
\hline $\begin{array}{l}\text { Other } \\
\text { None } \\
\text { Adontia } \\
\text { Incomplete denture } \\
\text { Beard } \\
\text { Short and wide neck } \\
\text { Prominent incisors } \\
\text { Anterior trachea } \\
\text { Long neck }\end{array}$ & $\begin{array}{c}128(92.8) \\
4(2.9) \\
1(0.7) \\
1(0.7) \\
1(0.7) \\
1(0.7) \\
1(0.7) \\
1(0.7)\end{array}$ \\
\hline
\end{tabular}

ASA: American society of anesthesiologists scale.

intubation in 114 patients (82.6\%), and POGOs of $100 \%$ were observed in 100 patients $(72.5 \%)$. (Table 2) Only one adverse event occurred in the study, which was an abrasion on the lip.

\section{Discussion}

One of the main challenges for the anesthesiologist, the medical specialist who is considered an expert in airway management, is the management of a difficult airway, either expected or not, by relying on different devices, laryngoscopies, curved and straight blades, stylet, interchanges, and laryngeal masks, as well as advanced devices such as the flexible and rigid fiberscopes and video laryngoscopy.

In the current literature, video laryngoscopy is presented as a tool and alternative for the management of difficult airways in patients. Adding to the basic conventional methods (laryngoscopy and laryngeal mask) and the advanced ones (flexible and rigid fiberscopes) as an alternative for the management of the patient, and therefore opening up a range of opportunities for the
Table 2. Laryngoscopy data

\begin{tabular}{|l|c|}
\hline Criterion & Value (\%) \\
\hline Successful intubation & $\mathrm{n}=138(99.2)$ \\
\hline $\begin{array}{l}\text { Number of attempts } \\
1\end{array}$ & $128(92.8)$ \\
2 & $9(6.5)$ \\
3 & $1(0.7)$ \\
\hline Intubation time & \\
$<30 \mathrm{~s}$ & $85(61.6)$ \\
$30 \mathrm{~s}-1$ min & $49(35.5)$ \\
$>1$ min & $4(2.9)$ \\
\hline Cormack-Lehane Observed & \\
\hline II & $114(82.6)$ \\
\hline P0G0 (\%) & $24(17.4)$ \\
\hline 50 & \\
75 & $6(4.3)$ \\
100 & $32(23.2)$ \\
External maneuvers & $100(72.5)$ \\
Adverse events & $53(38.4)$ \\
\hline
\end{tabular}

POGO: percentage of glottis observed.

anesthesiologist in his approach to the patient's airway ${ }^{8}$.

In this study, a modified device was tested, modified from a Macintosh \#3 blade similar to the one Dr. Kaddipacheril used in India in 2013, finding very similar results at a greater scale, due to the larger sample utilized in our study? ${ }^{7}$. However, in most revised studies, brand name video laryngoscopes were used, such as those made by Kingvision ${ }^{\circledR}$ and McGrath ${ }^{\circledR}$, among others.

In Argentina in 2018, under a similar concept, Cabrera-Massano et al. created a three-dimensional (3-D) printed device with a similar use with the help of a cellular phone as a monitor. Nevertheless, the 3D-printed device was only used in anatomical models and simulators of difficult airways without having an application or comparative studies with other devices ${ }^{9}$.

In 2017, Erdivanli et al. at Recep Tayyip Erdogan University, in Turkey, compared the Kingvision ${ }^{\circledR}$ video laryngoscope against a conventional Macintosh blade ${ }^{10}$ in a study conducted on 388 ASA I and II patients, where results between both were very similar, with King Vision ${ }^{\circledR}$ offering a better vision of the glottis compared to the Macintosh \#3 blade; however, a longer period of incubation time was observed with the King Vision ${ }^{\circledR}$ compared to the conventional blade. Taking this into consideration, it would be worthwhile to conduct a comparison of the Macintosh \#3 blade modified with King 


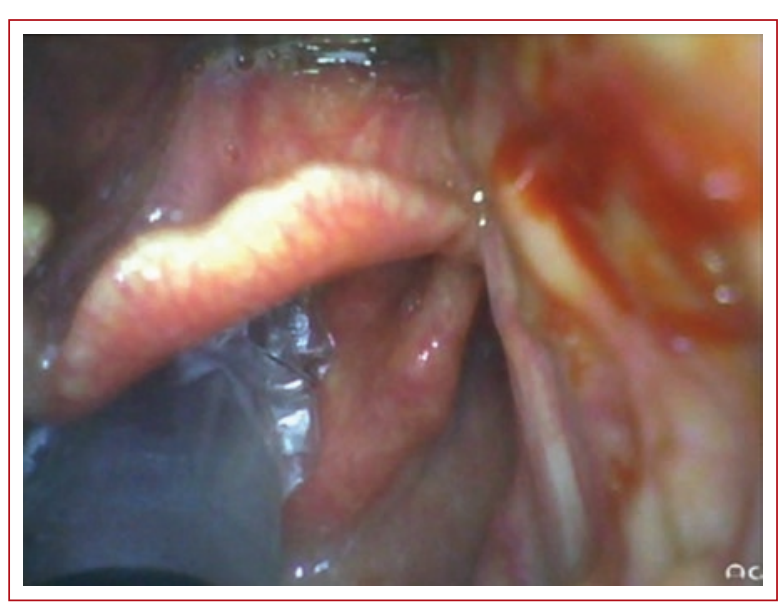

Figure 3. Intubation performed with the video laryngoscope. The image was taken during the intubation of a patient where the epiglottis and the insertion of the endotracheal tube can be observed. No vocal cords are observed in this image, only the glottic ring.

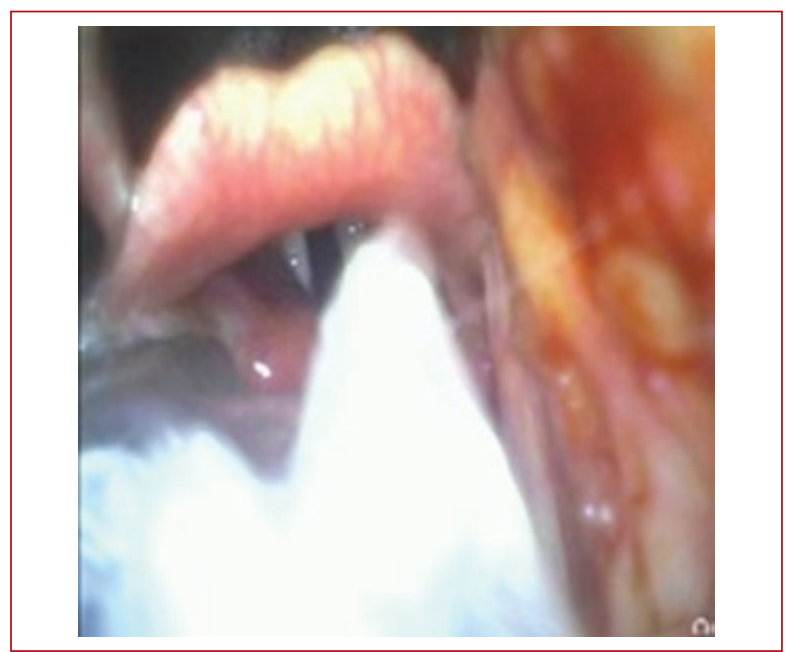

Figure 4. Intubation performed with the video laryngoscope. The image was taken during the intubation of a patient where the epiglottis can be observed with the insertion of the endotracheal tube. The vocal cords and glottic ring can be observed in this image.

Vision ${ }^{\circledR}$, due to the positive results of our study and considering that the use of a video camera ought to improve vision of the airway with the Macintosh \#3 blade; it should show very similar results to those of a King Vision ${ }^{\circledR}$ video laryngoscope.

Different advantages were found in the use of our device, allowing intubation in practically all patients who participated, a correct visualization of the glottic ring, attainment of good quality images (Figs. 3-5) and even

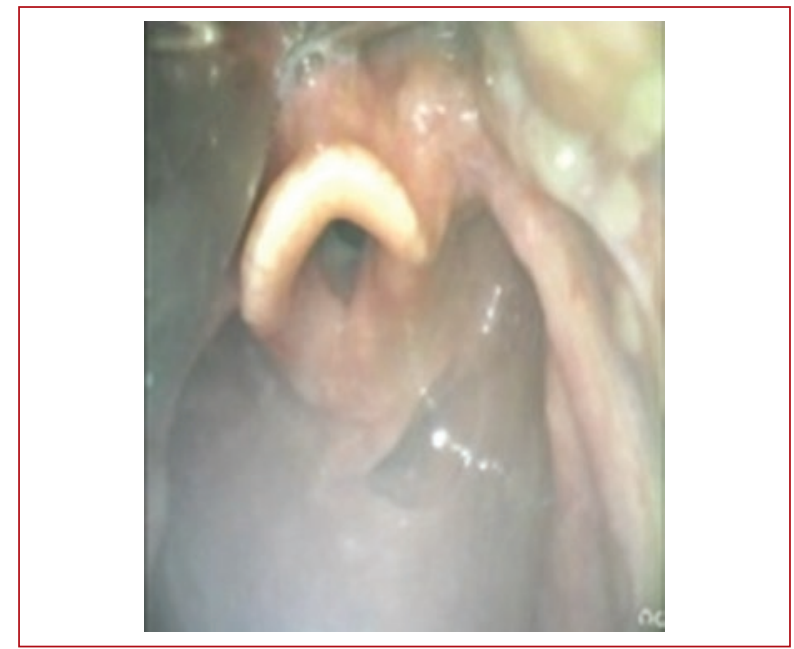

Figure 5. Glottic ring observed with the video laryngoscope. Glottic ring observed during laryngoscopy of one of the patients in the study. The epiglottis, as well as the glottic ring, is observed.

research on behalf of the professors affiliated with the service.

On the other hand, some aspects in which the device could be improved were found, which would help as feedback to modify it in the search of a better device, such as the size of the camera, which on many occasions and with an untrained assistant caused a delay in intubation time, the mobility of the support which held the monitor and the compatibility of the OS to use the necessary application for the correct functioning of the video camera.

\section{Conclusions}

It is worth noting that because of the good results shown by the study, it should be taken into consideration that the recruited patients in this study did not present data of a difficult airway, hence, its usefulness in the management of difficult airways could be subject to a study in a future protocol. Moreover, it is worth highlighting that just as in any device operated by medical personnel, the modified video laryngoscope in our service is operator-dependent, and success in the approach of the airway with the device will depend on the operator.

The video laryngoscope modified by our service from a conventional laryngoscope Macintosh \#3 blade proved to be helpful and safe. With the use of a cellphone screen as a monitor, where the visibility of the working area was viewed by the direct operator as well as the 
assistant team and personnel in training, it assisted in the management of the airway of the patient.

\section{Financing}

This research was funded with resources from the Universidad Autónoma de Nuevo León's Department of Anesthesiology of the "Dr. José Eleuterio González" University Hospital.

\section{Conflicts of interest}

The authors have no conflicts of interest to declare.

\section{Ethical disclosures}

Protection of human and animal subjects. The authors declare that no experiments were performed on humans or animals for this study.

Confidentiality of data. The authors declare that they have followed the protocols of their work center on the publication of patient data.

Right to privacy and informed consent. The authors have obtained the written informed consent of the patients or subjects mentioned in the article. The corresponding author is in possession of this document.

\section{References}

1. Rojas-Peñaloza J, Zapién-Madrigal JM, Athié-García JM, Chávez-Ruíz I, Bañuelos-Díaz GE, López-Gómez LA, et al. Manejo de via aerea. Rev Mex Anestesiol. 2017;40:s281-92.

2. Hagberg CA. Current concepts in the management of the difficult airway. Anesthesiol News. 2017;14:1-30

3. Frerk C, Mitchell VS, McNarry AF, Mendonca C, Bhagrath R, Patel A, et al. Difficult airway society 2015 guidelines for management of unanticipated difficult intubation in adults. Br J Anaesth. 2015;115:827-48.

4. Apfelbaum JL, Hagberg CA, Caplan RA, Blitt CD, Connis RT, Nickinovich DG, et al. Practice guidelines for management of the difficult airway: an updated report by the American society of anesthesiologists task force on management of the difficult airway. Anesthesiology. 2013; 118:251-70

5. Mosier JM, Whitmore SP, Bloom JW, Snyder LS, Graham LA, Carr GE, et al. Video laryngoscopy improves intubation success and reduces esophageal intubations compared to direct laryngoscopy in the medical intensive care unit. Crit Care. 2013;17:R237.

6. Griesdale DE, Chau A, Isac G, Ayas N, Foster D, Irwin C, et al. Video-laryngoscopy versus direct laryngoscopy in critically ill patients: a pilot randomized trial. Can J Anaesth. 2012;59:1032-9.

7. Karippacheril JG, Umesh G, Ramkumar V. Inexpensive video-laryngoscopy guided intubation using a personal computer: initial experience of a novel technique. J Clin Monit Comput. 2014;28:261-4.

8. Zaouter C, Calderon J, Hemmerling TM. Videolaryngoscopy as a new standard of care. Br J Anaesth. 2015;114:181-3.

9. Cabrera D, Massano G, Fernández S, Chaile S, Alday A, Patiño C, et al. Vídeo-laringoscopio de bajo costo desarrollado con tecnología de impresión 3D. unidad de $(i+d)$ biomodelos 3D hospital de niños de la Santísima Trinidad. Córdoba, Argentina. Rev Chil Anest. 2018;47:259-62.

10. Erdivanli B, Sen A, Batcik S, Koyuncu T, Kazdal H. Comparison of king vision video laryngoscope and Macintosh laryngoscope: a prospective randomized controlled clinical trial. Rev Bras Anestesiol. 2018;68:499-506. 